\title{
Acute Drug Pancreatitis: Azathioprine and Colchicine; About 2 Cases and Review of the Literature
}

\author{
S. Bouchrit ${ }^{1 *}$, Y. Lemfadli ${ }^{1}$, A. Ait Errami ${ }^{1}$, S. Oubaha ${ }^{1}$, Z. Samlani ${ }^{1}$, K. Krati ${ }^{1}$
}

${ }^{1}$ Gastro-Enterology Department, CHU Mohammed VI, Marrakech, Morocco

DOI: $10.36347 /$ sjmcr.2021.v09i04.004

| Received: 06.03.2021 | Accepted: 24.03.2021 | Published: 09.04.2021

*Corresponding author: S. Bouchrit

\section{Abstract}

Drug pancreatitis represented 0.1 to $2 \%$ of acute pancreatitis with more than 260 drugs implicated. The clinical and biological signs are not specific, the diagnosis is sometimes difficult based on the elimination of other causes of acute pancreatitis and the identification of the drug in question, the evolution is generally favorable after stopping the responsible drug. We report 2 cases of drug pancreatitis secondary to Azathioprine and colchicine.

Keywords: Acute pancreatitis, Drugs, Azathioprine, Colchicine.

Copyright $\odot 2021$ The Author(s): This is an open-access article distributed under the terms of the Creative Commons Attribution 4.0 International License (CC BY-NC 4.0) which permits unrestricted use, distribution, and reproduction in any medium for non-commercial use provided the original author and source are credited.

\section{INTRODUCTION}

Drugs are responsible for 0.1 to $2 \%$ of acute pancreatitis. The incidence of drug-induced pancreatitis is increasing with more than 260 treatments incriminated [1,2]. We report in this work 2 cases of acute drug-induced pancreatitis, one secondary to azathioprine in a patient followed by hemorrhagic ulcerative colitis in pancolitis and the 2 nd secondary to colchicine in a patient followed for Behçet's disease.

\section{CASE REPORT N ${ }^{\circ} 1$}

27-year-old patient, followed for UC in pancolitis retained on clinical, endoscopic and histological arguments, revealed by a first moderate attack and initially treated by oral corticosteroid therapy in degression and 5-ASA.

In view of the non-improvement, the management was to switch to azathioprine (Imurel*) at a dose of $2 \mathrm{mg} / \mathrm{kg} /$ day. 4 weeks later, the patient was admitted to the gastroenterology department for acute pancreatitis made up of acute epigastralgia for 3 days, early postprandial vomiting, a lipasemia greater than 3 times the normal (580 IU / 1) and a CRP at $128 \mathrm{mg} / 1$. abdominal CT revealed a stage B alithiasis Balthazar pancreatitis.

The diagnosis of pancreatitis secondary to azathioprine was made after ruling out other causes including lithiasis, alcoholic, metabolic, viral and autoimmune.
The decision was to discontinue azathioprine with good clinical outcome and switch to biotherapy (Infliximab) as a background treatment for UC.

\section{CASE REPORT N ${ }^{\circ}$}

A 33-year-old patient, followed for 2 years for Behçet's disease on colchicine, history of acute recurrent Balthazar stage B pancreatitis on 2 occasions and 5 months apart with no obvious aetiologies. Admitted to the emergency for acute epigastralgia progressing for 3 days, aggravated by food with early postprandial vomiting, CRP at $185 \mathrm{mg} / 1$, lipasemia at 9 times normal.

An abdominal CT scan performed showing stage A Balthazar pancreatitis, without dilation of the bile ducts within or outside the liver.

The etiological clinical-morphological assessment was without abnormalities, in particular:

- Lithiasis: no biological cholestasis and normal Bili-MRI no dilation of the bile ducts.

- Metabolic (calcemia, glycemia, phosphoremia): normal

- Viral (HVB, HVC, EBV, CMV, HIV): negative

- Autoimmune (AAN, igG4): negative

The drug origin was retained after eliminating the other causes already mentioned and the alcoholic origin. The outcome was favorable after stopping 
colchicine with regression of epigastralgia and resolution of vomiting.

The patient was then referred to the internal medicine services for additional management of her Behçet disease and therapeutic adjustment. After one year of monitoring, the patient did not have another episode of pancreatitis after definitive discontinuation of colchicine

\section{DISCUSSION}

Drug-induced pancreatitis is a generally benign entity with favorable outcome after discontinuation of the drug in question. The diagnosis of acute pancreatitis is often made before the association of a suggestive clinical picture and an increase in pancreatic enzymes, amylases and / or lipases, to more than four times the upper limit of normal, can reasonably be expected to pose the diagnosis of acute pancreatitis [3].

The drug origin of pancreatitis is more difficult to establish. It is mainly based on the elimination of other causes, the most common are alcoholic, lithiasic and metabolic and the notion of introducing or increasing the dose of a given drug.

Drug-induced pancreatitis accounts for 1-2\% of all pancreatitis $[1,4]$. In Morocco there is no current data on its prevalence. Most often it is a benign pathology with a favorable course after elimination of the drug in question. Currently more than 260 treatments are incriminated, the physiopathological mechanism is not clearly elucidated. It could be an immunoallergic reaction, direct cytotoxicity on pancreatic cells or ischemia of the pancreatic gland [2].

In 1999, the Pancreatox ${ }^{\circledR}$ database was made up of 994 articles analyzed and validated which incriminated 230 drugs in the occurrence of 2,766 cases of biological pancreatitis and 2,572 cases of acute pancreatitis. The most frequently involved pharmacotherapeutic classes were antiinfectives (57 times), anticancer drugs (36 times), drugs used in cardioangiology (31 times), in rheumatology (21 times) or in neurology (17 times) [5]. In France, 52 marketed drugs are incriminated, at least once, in the occurrence of biological pancreatitis is presented in Table 1 [5].

Table-1: List of 52 drugs marketed in France and incriminated in the occurrence of biological pancreatic damage [5]

\begin{tabular}{|l|l|l|}
\hline Valproic Acid, Meglumine & Dapsone, Diazoxide, & Pentamidine, Prednisolone \\
Antimonate & Diclofenac, Didanosine & Pyrimethamine + Dapsone \\
Apomorphine, Asparaginase & Ephedrine, Erythromycin & Rifampicin, Roxithromycin \\
Atovaquone, Azathioprine & Estrogen-progestogens & Saquinavir, Sparfloxacin \\
Bethanechol, Bumetanide & Hydrochlorothiazide Interferon & Stavudine, Sulfafurazole \\
Cefamandole, Cefixime & alfa 2b Iodixanol Lamivudine, & Sulfasalazine, Sulindac \\
Ciclosporine, Ciprofloxacin & Lanreotide Lithium, Mesalazine & Tamoxifen, Tetracycline \\
Cisapride, Cisplatin & Methylprednisolone, Morphine, & Tretinoine, Zalcitabine Zidovudine \\
Cladribine, Clozapine & Nevirapine Paracetamol & \\
Codeine, Cotrimoxazole & & \\
\hline
\end{tabular}

In our specialty and in view of the wide use of azathioprine in chronic inflammatory bowel disease, acute pancreatitis remains one of the non-dose dependent allergic side effects (3\% of cases). Several cases were published but with a generally favorable response after stopping treatment. Unlike colchicine, there are very few published cases.

The implication of a drug in the triggering of pancreatitis is based on a body of arguments. The exact chronology of the evolution of the symptoms compared to the administration, the discontinuation and possibly the reintroduction of the drug remains the essential element for the diagnostic orientation [6]. The shorter the time to onset of acute pancreatitis compared to drug intake, the more likely it is to blame. And the more the symptoms disappear when it is stopped and resume when it is introduced, the more the product is incriminated.

\section{CONCLUSION}

Drug-induced pancreatitis is currently a wellknown entity, several drugs are involved, among others azathioprine and rarely colchicine. Its diagnosis is based on the elimination of other causes of acute pancreatitis and the identification of the drug in question, the clinical-biological sings are not specific, the evolution after stopping the drug in question is generally favorable.

\section{REFERENCES}

1. Mc Donald KB, Garber B, Perreault M. Pancreatitis associated with simvastatin plus fenofibrate. Ann Pharmacother. 2002;36(2):275-9.

2. Tysk C, Al-Eryani AY, Shawabkeh AA. Acute pancreatitis induced by fluvastatintherapy. J Clin Gastroenterol. 2002;35(5):406-8.

3. Delcenserie R., Grangé J.D., Laugier R., Bernades P. Definition and accountability criteria for acute drug-induced pancreatic damage. Gastroenterol Clin Biol $1992 ; 16: 761-3$ 
S. Bouchrit et al., Sch J Med Case Rep, Apr, 2021; 9(4): 326-328

4. Tenner S. Drug-induced acute pancreatitis: underdiagnosis and overdiagnosis. Dig Dis Sci. 2010;55(10):2706-8.

5. M. Biour, J.D. Grangé, Acute drug-induced pancreatic disease, Act. Med. Int. Gastroenterology (13), n ${ }^{\circ}$ 9, November 1999.
6. Biour M, Delcenserie R, Grange JD, Weissenburger J. Pancreatotoxicity of drugs Gastroenterol Clin Biol. 2001 Jan;25(1 Suppl):1S22-7. 